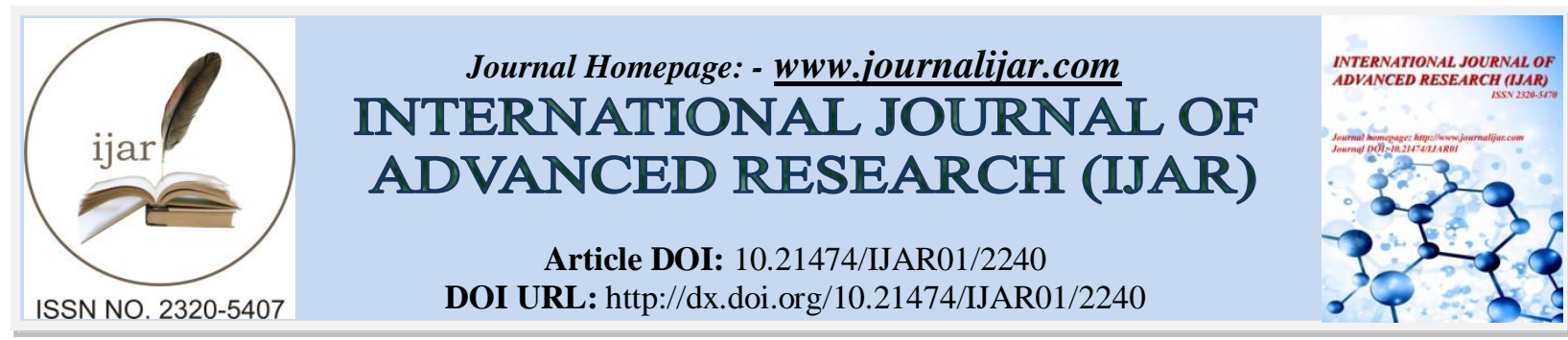

RESEARCH ARTICLE

\title{
COMPARATIVE STUDY BETWEEN ORAL PENICILLIN AND LONG ACTING PENICILLIN IN TREATMENT OF RECURRENT STREPTOCOCCAL TONSILLOPHARYNGITIS.
}

\author{
Shahin Aly Dabour ${ }^{1}$, Yaser Mahmud Ismail ${ }^{2}$, Effat Hussein Assar ${ }^{1}$, Eman R. Abd Almonaem ${ }^{1}$ and Hatem \\ Hamid Yousef ${ }^{1}$. \\ 1. Pediatric department, Faculty of medicine, Banha University, Qalyubia, Egypt. \\ 2. Clinical pathology department, Faculty of medicine, Banha University, Qalyubia, Egypt.
}

\section{Manuscript Info}

\section{Manuscript History}

Received: 29 September 2016

Final Accepted: 30 October 2016

Published: November 2016

Key words:-

Pharyngitis, Streptococci, oral penicillin, Benzathin penicillin.

\section{Abstract}

Background and objectives:- Antimicrobial treatment of GABHS pharyngitis is aimed at reduction of poststreptococcal complications, symptoms, duration, and disease spread. The main goal of our study will be to assess the effect of therapy by long acting penicillin single injection per month versus oral penicillin for 10 days in treatment of children with recurrent streptococcal tonsillopharyngitis by frequent estimation of antistreptolysin o titre (ASOT).

Method: Prospective study was done on 50 children suffering from recurrent follicular tonsillitis with high level of anti-streptococcal antibodies (ASOT) (>400 Todd units), age ranges from 3 to 13 years. . The children were classified into 2 groups, group (1) included 25 children had been treated with oral penicillin V (phenoxy methyl penicillin) $10 \mathrm{mg} / \mathrm{kg} /$ day for 10 days. Group (2) included 25 children had been treated with long acting penicillin single injection of 1.200.000 IU for children $>25 \mathrm{KG}$ and $600.000 \mathrm{IU}$ for those $<25 \mathrm{KG}$. Follow up of the children was done by assessment of ASOT at 3months and 6 months in both groups.

Results: There was significant reduction in the level of ASOT at 3 and 6 months in both groups in comparison to the level at the time of presentation, however there was no significant difference between the both groups at 3 and 6 months as regards ASOT level.

Conclusions: Penicillin remains the treatment of choice for treatment of (GABHS) pharyngitis. There is no difference between oral penicillin and long acting penicillin in treatment of (GABHS) pharyngitis. There was no relationship between the level of ASO titers and the clinical manifestation of (GABHS) pharyngitis.

Copy Right, IJAR, 2016,. All rights reserved.

\section{Introduction:-}

Recurrent pharyngitis is a very common complaint in the pediatric population. It is a persistent clinical problem that causes repeated use of antibiotics and a significant burden on both families (absences from school or work) and societies (health care costs). ${ }^{[1]}$ Although the disease appears to be self-limited in most cases, the risk for suppurative and non-suppurative complications is still a worrying issue ${ }^{[2]}$ Even without these complications, the disease still adds a heavy socioeconomic burden. ${ }^{[3]}$ While recurrent pharyngitis often begins as viral infections, bacterial

Address: - Pediatric department, Faculty of medicine, Banha University, Qalyubia, Egypt. 
infections is observed in $60 \%$ of patients with upper respiratory tract symptoms lasting at least 10 days. ${ }^{[4]}$ Several bacterial etiological agents have been identified and frequently isolated from the tonsillar core including; Streptococcus pyogenes, Staphylococcus aureus, Streptococcus pneumoniae, and Haemophilus. Influenza. ${ }^{\text {[5] }}$ Group A beta-hemolytic streptococcus (GABHS) is the most important pathogenic bacterial etiology and has been the focus of diagnostic and therapeutic efforts aimed at reducing its risk of both suppurative (quinsy, acute otitis media, acute sinusitis) and nonsuppurative complications (e.g. acute rheumatic fever, acute glomerulonephritis) if left untreated. ${ }^{[2]}$ Unfortunately, the lack of an effective immunization, the persistence or recurrences of an infection despite an optimal treatment have made secondary prevention by continuous antimicrobial prophylaxis, the only means of protecting at risk individuals. ${ }^{[6]}$ The American Heart Association, the American Academy of Pediatrics, and the Infectious Diseases Society of America have always recommended either a monthly ten days course of oral penicillin V (2 to 4 times a day) or a monthly single intramuscular injection of benzathine benzyl penicillin as the mainstay therapy in patients without penicillin allergy. ${ }^{[7]}$ This is simply due to its cost effectiveness, narrow spectrum of activity and long standing proven efficacy in elimination of GABHS and prevention of rheumatic fever . Furthermore, according to a recent systematic review, to date, no penicillin-resistance has been documented. ${ }^{[8]}$ However, the monthly IM injection of benzathine penicillin has not gained wide acceptance, largely because of frequent prolonged pain at the site of injection and increased risk of side effects, which led some individuals to discontinue prophylaxis. For this reason in clinical practice, most physicians viewed oral therapy to be more advantageous over parenteral treatment by reducing patient discomfort, needle-associated complications, providing shorter exposure to the medication, and less severe allergic reactions. ${ }^{[9]}$ However, poor patient compliance to the multiply dosed oral penicillin V (2 to 3 times daily for 10 days each month) jeopardized the whole treatment success where most failures occurred in non-adherent patients. ${ }^{[10]}$ Furthermore, several attempts to use a once daily oral dose of penicillin $\mathrm{V}$ to effectively treat pharyngitis have failed. ${ }^{[11]}$ However, it has been reported that tonsillectomy modestly reduces the number of episodes and days with sore throat in both children and adults. ${ }^{\text {[12] }}$

\section{Patients and method:- \\ Patients:-}

Prospective study was done on 50 children suffering from recurrent follicular tonsillitis with high level of antistreptococcal antibodies (ASOT) (>400 Todd units), age ranges from 3 to 13 years.Subjects were diagnosed by fever, sore throat, vomiting, and headache, with or without tender anterior cervical nodes. The children were classified into 2 groups, group (1) included 25 children had been treated with oral penicillin V (phenoxy methyl penicillin) $10 \mathrm{mg} / \mathrm{kg}$ for 10 days. Group (2) included 25 children had been treated with long acting penicillin single injection of 1.200.000 IU for children $>25 \mathrm{KG}$ and $600.000 \mathrm{IU}$ for those $<25 \mathrm{KG}$. Follow up of the children was done by assessment of ASOT at 3months and 6 months in both groups.

\section{All patients will be subjected to:-}

Full medical history taking,. Thorough clinical examination,Clinical scoring system (Sore throat score approach) to evaluate patients who present with sore throats, has been developed for use in community-based family practice. The goal of this approach is to identify and treat GAS infections in order to prevent the squeals of these infections ${ }^{\text {[13] }}$ and measurement of serum anti streptococcal antibodies (ASOT), complete blood count, erythrocyte sedimentation rate (ESR), C reactive protein (CRP). ASOT was done at presentation, 3 months and 6 months. Venous blood samples were collected from the studied children at presentation, 3months and 6month. The samples were allowed to settle and form a clot, and then centrifuged to collect the clear sera. Hemolysed, contaminated, or lipaemic sera were excluded. Sera were stored at $2^{\circ} \mathrm{C}$ to $8^{\circ} \mathrm{C}$ for up to 48 hours prior to testing by Latex serology test for detection of Streptococcal Antibodies. The reagent was brought to room temperature and mixed gently to resuspend latex prior to use. Isotonic saline was then used to prepare serial dilutions of the sera $(1 / 2,1 / 4,1 / 8$, and so on). One drop of each serum dilution was then transferred to test circle on the slide and one drop of the reagent was added to each circle and mixed with the diluted sera. Gently and evenly, the test slide was rocked and rotated for 2 minutes whilst examining the test slide for agglutination. The serum ASO concentration was then calculated by multiplying the dilution factor (i.e. $2,4,8 \ldots$ ) by the detection limit (200) to give the number of IU/ml concentration. ${ }^{\text {[14] }}$

\section{Statistical analysis:-}

Data was analyzed using statistical package of social science (SPSS).

\section{Results:-}

This study was conducted on 50 children (age ranges from 3 to 13) years. The children were presented with signs and symptoms suggestive of streptococcal pharyngitis with history of recurrent follicular tonsillitis and high ASOT 
level. The children were classified into 2 groups, group (1) included 25 children had been treated with oral penicillin for 10 days, group (2) included 25 children had been treated with long acting penicillin. Our results showed that there was significant reduction in the level of ASOT at 3 and 6 months in both groups in comparison to the level at the time of presentation, however there was no significant difference between the both groups at 3 and 6 months as regards ASOT level. The ASOT of children in group (1) at presentation was $560.000 \pm 141.421 \mathrm{Iu} / \mathrm{ml} \mathrm{with} \mathrm{range}$ from $400-800 \mathrm{Iu} / \mathrm{ml}$ while it was $219.000 \pm 55.522 \mathrm{Iu} / \mathrm{ml}$ with range from $160-400 \mathrm{Iu} / \mathrm{ml}$ at 3 months and $194.400 \pm$ $45.651 \mathrm{Iu} / \mathrm{ml}$ with range from 160- $400 \mathrm{Iu} / \mathrm{ml}$ at 6 months. The ASOT of children in group (2) at presentation was $560.000 \pm 129.099 \mathrm{Iu} / \mathrm{ml}$ with range from $400-800 \mathrm{Iu} / \mathrm{ml}$ while it was $194.400 \pm 45.651 \mathrm{Iu} / \mathrm{ml}$ with range from 160 $400 \mathrm{Iu} / \mathrm{ml}$ in children at 3 months and $191.200 \pm 64.312 \mathrm{Iu} / \mathrm{ml}$ with range from $160-400 \mathrm{Iu} / \mathrm{ml}$ at 6 months.

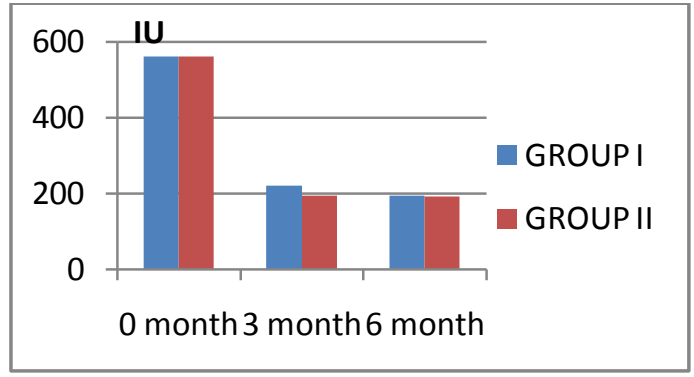

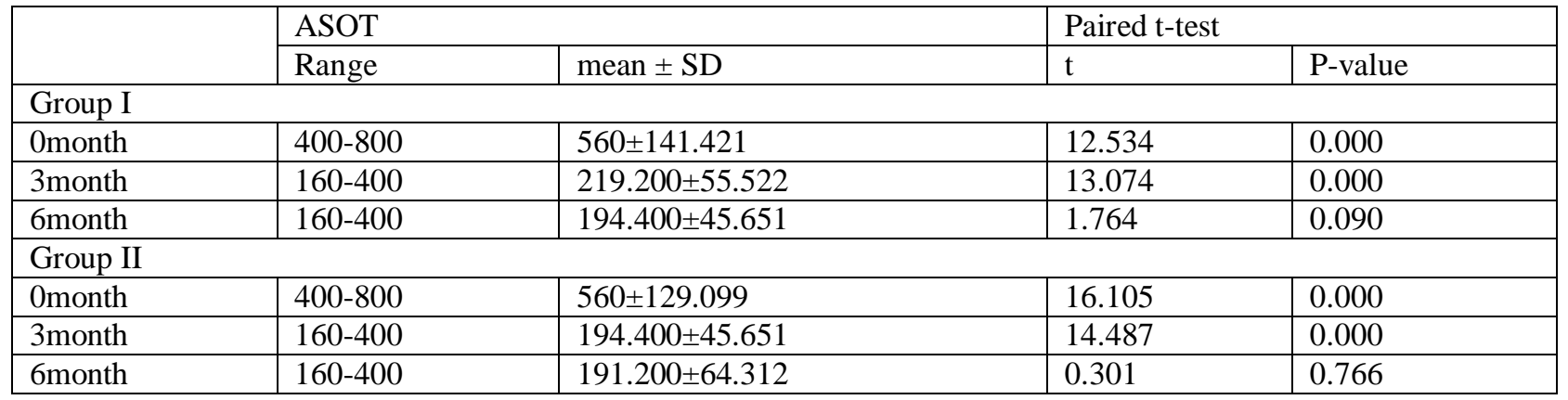

According to age distribution in our study, there was no significant difference between the 2 groups as regards age

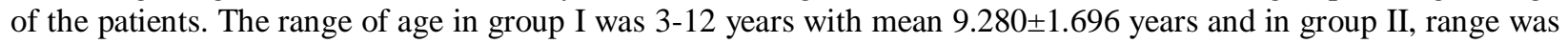
4-13years with mean age $9.960 \pm 1.791$ years. Age of this sample show children between 5-10 years was 243 $(64.6 \%)$ more than children between $11-15$ year $133(35.3 \%)$.

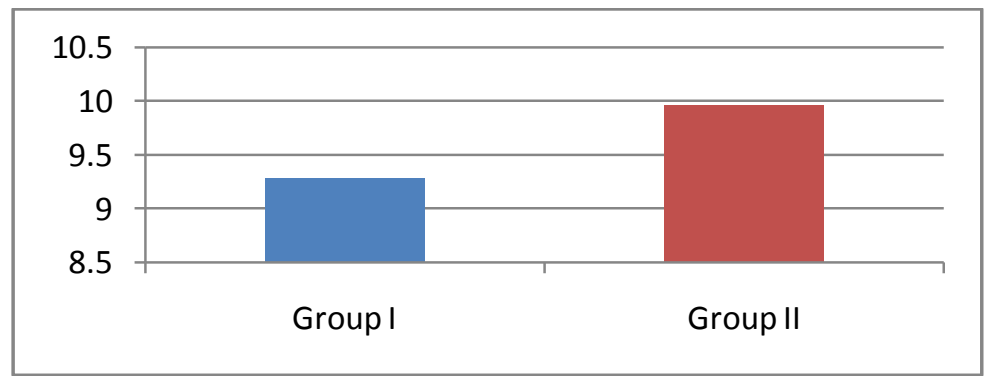

\begin{tabular}{|l|l|l|l|l|}
\hline \multirow{2}{*}{} & \multicolumn{2}{|l|}{ Age(years) } & \multicolumn{2}{l|}{ T-test } \\
\cline { 2 - 3 } & Range & Mean \pm SD & t & P-value \\
\hline Group I & $3-12$ & $9.280 \pm 1.696$ & -1.379 & 0.174 \\
\hline Group II & $4-13$ & $9.960 \pm 1.791$ & & \\
\hline
\end{tabular}

Sex distribution in our study Male to female ratio was 1: 1.17 (23 males: 27 females) and there was no significant difference between the 2 groups as regards sex of the patients. In group I male to female ratio was 1: 1.083(12 males to 13 females) and group II 1:1.27 (11 males: 14 female). 


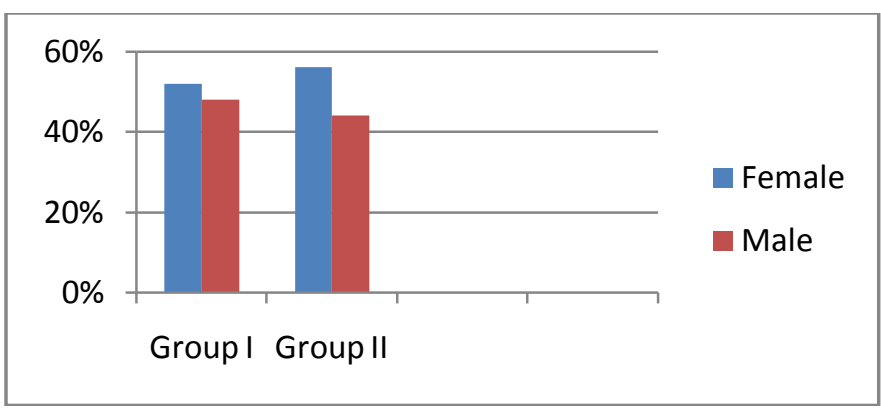

\begin{tabular}{|c|c|c|c|c|c|c|}
\hline \multirow[t]{3}{*}{ Sex } & \multicolumn{6}{|c|}{ Groups } \\
\hline & \multicolumn{2}{|c|}{ Group I } & \multicolumn{2}{|c|}{ Group II } & \multicolumn{2}{|c|}{ Total } \\
\hline & $\mathrm{N}$ & $\%$ & $\mathrm{~N}$ & $\%$ & $\mathrm{~N}$ & $\%$ \\
\hline Female & 13 & 52 & 14 & 56 & 27 & 54 \\
\hline Male & 12 & \begin{tabular}{|l|}
48 \\
\end{tabular} & 11 & 44 & 23 & 46 \\
\hline Total & 25 & 100 & 25 & 100 & 50 & 100 \\
\hline \multirow[t]{2}{*}{ Chi-square } & \multicolumn{2}{|l|}{$X^{2}$} & \multicolumn{4}{|c|}{0.000} \\
\hline & \multicolumn{2}{|c|}{ P-value } & \multicolumn{4}{|c|}{1.000} \\
\hline
\end{tabular}

There was no significant difference between the 2 groups as regards number family member of the patients. The highest number was 8 members with percentage $10 \%$ in of all and lowest was 4 members represented $24 \%$ of all.

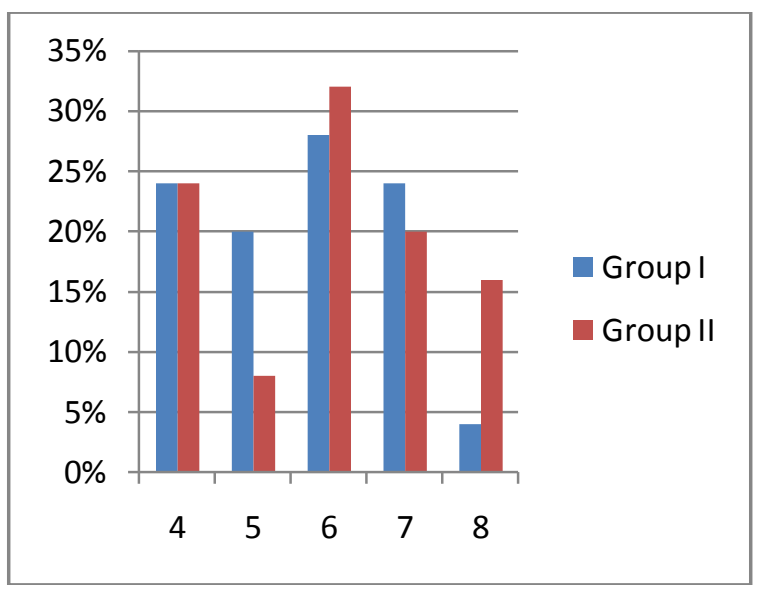

\begin{tabular}{|c|c|c|c|c|c|c|c|}
\hline \multirow{3}{*}{\multicolumn{2}{|c|}{ No family members }} & \multicolumn{6}{|c|}{ Groups } \\
\hline & & \multicolumn{2}{|c|}{ Group I } & \multicolumn{2}{|c|}{ Group II } & \multicolumn{2}{|c|}{ Total } \\
\hline & & $\mathbf{N}$ & $\%$ & $\mathbf{N}$ & $\%$ & $\mathbf{N}$ & $\%$ \\
\hline \multicolumn{2}{|l|}{4} & 6 & 24 & 6 & 24 & 12 & 24 \\
\hline \multicolumn{2}{|l|}{5} & 5 & 20 & 2 & 8 & 7 & 14 \\
\hline \multicolumn{2}{|l|}{6} & 7 & 28 & 8 & 32 & 15 & 30 \\
\hline \multicolumn{2}{|l|}{7} & 6 & 24 & 5 & 20 & 11 & 22 \\
\hline \multicolumn{2}{|l|}{8} & 1 & 4 & 4 & 16 & 5 & 10 \\
\hline \multicolumn{2}{|l|}{ Total } & 25 & 100 & 25 & 100 & 50 & 100 \\
\hline \multirow[t]{2}{*}{ Chi-square } & $\mathbf{X}^{2}$ & \multicolumn{6}{|c|}{3.243} \\
\hline & P-value & \multicolumn{6}{|c|}{0.518} \\
\hline
\end{tabular}

During the follow up of both groups as regard recurrent attacks of acute pharyngitis during the sixth months study there was one child at each group had got another attack of acute pharyngitis which had been treated with oral penicillin, so recurrence rate of acute pharyngitis in both groups was $4 \%$.

\section{Discussion:-}

The treatment of GAS pharyngitis is directed towards eradication of the bacteria from the upper respiratory tract. The infection can usually be eradicated by a single intramuscular injection of benzathine benzylpenicillin or by 10 
days' treatment with oral penicillin. ${ }^{[43]}$ Our study was done to evaluate effectiveness of oral penicillin for 10 days against single injection of long acting penicillin in eradication of streptococcal pharyngitis. This study was done on 50 children with clinical picture suggesting streptococcal pharyngitis by using sore throat score and high ASOT. In our study there was no significant difference between 2 groups with failure rate $4 \%$ in both. Some studies show that failure rate with oral penicillin reach $37 \%$ in $2001^{[15]}$ and $38 \%$ in $2003^{[16]}$ and $37-42 \%$ failure rate in eradication of GAS from the tonsillopharynx following the use of injectable benzathine penicillin. ${ }^{[15]}$ poor compliance, inadequate dose, lack of GAS serotyping and/or serological studies have been offered as explanations for the drop in eradication of GAS with penicillin in efficacy trials. ${ }^{[17]}$ In this study the sex proportion was 1:1.17 favouring females (54\% females), This agreed with many studies that reported the greater proportion of female patient's eg. Nirmal Kushwaha found that male to female 1:1.12(53\% female). ${ }^{[18]}$ But Lin et al found that group A streptococcal pharyngitis a slightly higher incidence in boys. Of 1175 throat cultures obtained, GAS was isolated in 252 cases (21.4\%). Of these, $142(56.3 \%)$ were boys and $110(43.7 \%)$ girls. ${ }^{[19]}$ Sobhan et al found that there was no significant difference in the incidence of sore throat or GAS sore throat between males and females. ${ }^{[20]}$ The age of children in our study was between 3-13 years with $62.9 \%$ of children between 5 and 10 years. This agrees with Fadwa et al. Of 376 Iraqi patients with streptococcal tonsillitis and other healthy carriers for group A streptococci, age of this sample show children between 5-10 years was 243 (64.6\%) more than children between 11-15 year 133 $(35.3 \%) .{ }^{[21]}$ However, older age (11 years) has been reported in a study in India. ${ }^{[22]}$ Higher number of family members in our study is an index of overcrowdings that favors the transmission of group A streptococcal infection. Individuals of all ages are susceptible to the propagation of this microorganism in conditions of overcrowding, as its interpersonal dissemination occurs through sputter or by direct contact, mainly in environments where large crowds get together. ${ }^{[23]}$

\section{Conclusion:-}

The crucial role of multiple components of the innate immune system in controlling GAS infection and preventing serious disease outcomes, including epithelial barrier function, antimicrobial peptides, the complement system, and phagocytic cells, including neutrophils and macrophages, is being revealed. Despite intensive efforts and considerable new information, the molecular mechanisms of GAS immune sequelae such as ARF and poststreptococcal glomerulonephritis remain to be conclusively defined. The resistance of GAS to antibiotics other than penicillins and cephalosporins is an increasing concern. ASO reaction is an important laboratory test which can determine the status of Group A Streptococcal infection; in specific cases association of other laboratory tests such as antistreptokinase, antihyaluronidase, antidiphosphopydrine-nucleotidase (anti -DPNase), antidesoxyribonuclease B (antiDNAse B) might be needed in order to provide a more complete evaluation of these patients. The main goals in our study were to assess the effect of therapy by oral penicillin for 10 days versus long acting penicillin single injection $1.200 .000 \mathrm{IU}$ for children $>25 \mathrm{KG}$ and $600.000 \mathrm{IU}$ for children $<25 \mathrm{KG}$ in treatement of children with recurrent follicular tonsillitis by frequent estimation of antistreptolysin o titre (ASOT). This study supports that :Penicillin either oral or long acting penicillin remains the treatment of choice for treatment of (GABHS) pharyngitis.There was no relationship between the level of ASO titers and the clinical manifestation of (GABHS) pharyngitis.There is no difference between oral penicillin and long acting penicillin in treatment of (GABHS) pharyngitis.

\section{Recommendations:-}

Patient's family must be instructed to complete the full course of antibiotic therapy, as improvement may occur rapidly.Patient's family should be instructed to follow up when indicated. Instruct families to encourage adequate hydration and to use antipyretics for pain and fever. In addition, instruct parents to seek immediate medical care or consult their primary medical provider if signs of dehydration occur or symptoms worsen. Patient's family should be educated about symptomatic treatment of pharyngitis. Ibuprofen or acetaminophen is recommended for analgesia. Saltwater gargle, warm liquids, and rest may be helpful in relieving symptoms.A standardized protocol needs to be established at each institution or emergency department to ensure follow-up for patients with pending throat cultures. A follow-up culture should be taken if history or evidence of rheumatic fever or if symptoms are consistent with a relapse. Patients with infectious mononucleosis should be instructed to follow up with their physician in 1 week. These patients should also be advised to avoid contact sports. Regular and periodic evaluation of ASO titers should be done in the community, taking into consideration, changing epidemiological patterns of streptococcal infections and seasonal effects. Using high ASO titers is more reliable in diagnosis of post streptococcal infection. Early detection, correct diagnosis and appropriate treatment of individual patients with Group A streptococcal pharyngitis. Health education is done to the population about the modes of transmission of streptococcal infection. 
We recommend that GAS carriers do not ordinarily justify efforts to identify them nor do they generally require antimicrobial therapy. We do not recommend tonsillectomy solely to reduce the frequency of GAS pharyngitis

Future research should focus on the following: Improved rapid methods for diagnosis of acute GAS pharyngitis and for distinguishing acute infection from chronic pharyngeal carriage, development of simpler or shorter therapeutic regimens for acute GAS pharyngitis, and development of an affordable, safe, and effective GAS vaccine against the broad spectrum of GAS organisms, and development of a future GAS vaccine for use in humans.

\section{Reference:-}

1. Koskenkorva T, Koivunen P, Koskela M, et al,2013. Short-term outcomes of tonsillectomy in adult patients with recurrent pharyngitis: a randomized controlled trial. CMAJ. 2013;185(8):331-6.

2. Sarrell EM, and Giveon SM, 2012. Streptococcal pharyngitis: a prospective study of compliance and complications. ISRN Pediatrics. 2012;2012:796389.

3. Pfoh E, Wessels M, Goldmann D, et al,2008. Burden and economic cost of group A streptococcal pharyngitis. Pediatrics. 2008;121:229-34.

4. Angelo S, Massimo D, Barbara C, et al, 2008. Sulphurous water inhalations in the prophylaxis of recurrent upper respiratory tract infections. Int J Pediatr Otorhinolaryngol. 2008;72:1717-22.

5. Klug TE, Henriksen JJ, Fuursted K, et al (2011). Significant pathogens in peritonsillar abscesses. Eur J Clin Microbiol Infect Dis. May;30(5):619-627. doi: 10.1007/s10096-010-1130-9.

6. Gerber MA, Baltimore RS, Eaton CB, et al ( 2009). Prevention of rheumatic fever and diagnosis and treatment of acute streptococcal pharyngitis: a scientific statement from the American Heart Association Rheumatic Fever, Endocarditis, and Kawasaki Disease Committee of the Council on Cardiovascular Disease in the Young, the Interdisciplinary Council on Functional Genomics and Translational Biology, and the Interdisciplinary Council on Quality of Care and Outcomes Research. Endorsed by the American Academy of Pediatrics. Circulation 119:1541-1551. 10.1161/CIRCULATIONAHA.109.191959

7. Shulman ST, Bisno AL, Clegg HW, et al (2012). Clinical practice guideline for the diagnosis and management of group A streptococcal pharyngitis: update by the Infectious Diseases Society of America. Clin Infect Dis 2012;55:1279-82.

8. van Driel ML, De Sutter AI, Keber N, et al (2013). Different antibiotic treatments for group A streptococcal pharyngitis. Cochrane Database Syst Rev. ;4:CD004406. doi: 10.1002/14651858.CD004406.pub3.

9. Baltimore R(2010). Re-evaluation of antibiotic treatment of strep- tococcal pharyngitis. Curr Opin Pediatr. 2010;22:77-82.

10. Gerber MA .(2001). New approaches to the treatment of group A streptococcal pharyngitis. Curr Opin Pediatr. 2001;13(1):51-5.

11. Robertson KA, Volmink JA, and Mayosi BM (2005). Lack of adherence to the national guidelines on the prevention of rheumatic fever. S Afr Med J. 2005;95:52-56.

12. Baugh RF, Archer SM, Mitchell RB, et al, 2011. Clinical practice guideline: tonsillectomy in children. Otolaryngology--head and neck surgery : official journal of American Academy of Otolaryngology-Head and Neck Surgery. 2011;144(1):1-30.

13. McIsaac WJ, Goel V, Low DE, et al (2000). The validity of a sore throat score in family practice. CMAJ. 2000;163(7):811-815.

14. Kilian M (2002). Streptococcus in; Medical Microbiology in: Greenwood D, Salak Rc, Peutherer JF (eds.). A textbook of Medical Microbiology, $16^{\text {th }}$ edition. China, Churchill Livingston. P: 174-88.

15. Kaplan E, and Johnson D (2001). Unexplained reduced microbiological efficacy of intramuscular benzathine penicillin $\mathrm{G}$ and oral penicillin $\mathrm{V}$ in eradication of group $\mathrm{A}$ streptococci from children with acute pharyngitis. Pediatrics 108:1180-1186

16. Curtin-Wirt C, Casey J, Murray $\mathbf{P}$ et al (2003). Efficacy of penicillin vs. amoxicillin in children with group A beta hemolytic streptococcal tonsillopharyngitis. Clin Pediatr 42:219-225

17. Shulman S, and Gerber M (2004). So what's wrong with penicillin for strep throat? Pediatrics 113:1816-1

18. Nirma Kushwaha, Madhumati Kamat, Bijendra Banjade, et al (2014). Prevalence of Group-A Streptococcal Infection Among Schoo Children of Urban Community. International Journal of Interdisciplinary and Multidisciplinary Studies (IJIMS), Vol 1, No.5, 249-2561

19. Lin MH, Chang PF, Fong WK, et al(2003). Epidemiological and clinical features of group A streptococcus pharyngitis in children. Acta paediatr Taiwan 2003:44:274-8. 
20. Sobhan Nandi, Rajesh Kumar,Pallab Ray,et al(2001). Group A streptococcal sore throat in a periurban population of northern India: a one-year prospective study. Bull World Health Organ vol. 79 n. 6 Genebra Jan. 2001

21. Fadwa Abd Al-Kareem, Aruba Abbas, Median Hussein (2014). Comparative study of the Antibody Responses to Streptococcus pyogenes between school Children carriers and patients with Tonsillitis. Iraqi Journal of Science, 2014, Vol 55, No.2A, pp:403-410-

22. Nandi, S., Kumar, R., Ray, P., Vohra H., et al(2001). Group A streptococcal sore throat in a periurban population of northern India: a one-year prospective study. Bulletin of the World Health Organization 79, 528533

23. Cunningham MW(2000). Pathogenesis of Group A streptococcal infections. Clin Microbiol Rev. 2000;13(3):470-511. 